\title{
Behavioural effects of chronic exposure to sub- anesthetic concentrations of halothane, sevoflu- rane and desflurane in rats
}

\author{
[Effets comportementaux d'une exposition chronique à des concentrations \\ sous-anesthésiques d'halothane, de sévoflurane et de desflurane chez les rats]
}

Murat Ozer MD, Sibel Baris MD, Deniz Karakaya MD, Serhat Kocamanoglu MD, Ayla Tur MD

Background: A double-blind, randomized trial was conducted to determine the behavioural effects of chronic exposure to subanesthetic concentrations of halothane, sevoflurane and desflurane in rats.

Methods: Halothane, sevoflurane and desflurane group rats received $0.1 \%, 0.3 \%$, and $0.6 \%$ concentrations in a flow rate of $3 \mathrm{~L} \cdot \mathrm{min}^{-1} \mathrm{O}_{2}$, respectively. Control animals also received 3 $\mathrm{L} \cdot \mathrm{min}^{-1} \mathrm{O}_{2}$ in another investigation room, which had the same properties as the study group rooms. Rats breathed inhaled agents or oxygen between 09:00-13:00 hr every day for 30 days. After 30 days of inhalation of subanesthetic doses of inhaled agents or oxygen, behavioural tests were applied.

Results: Tests of exploratory activity and curiosity (hole-board test), anxiety (elevated plus maze test) and learning and memory functions (multiple T maze test), demonstrated that chronic exposure to subanesthetic concentrations of all three anesthetics alters behavioural functions in rats. However, impairment of learning $(P<0.05)$ and memory function $(P<0.05)$ were greater in association with desflurane, in comparison to halothane and sevoflurane-treated rats.

Conclusion: Chronic exposure to subanesthetic concentrations of halothane, sevoflurane and desflurane is associated with behavioural change in rats. Of the three drugs, desflurane was associated with the lowest learning and memory function test scores.

Objectif: Déterminer, par une étude randomisée à double insu, les effets comportementaux de l'exposition chronique à des concentrations sous-anesthésiques d'halothane, de sévoflurane et de desflurane chez les rats.
Méthode : L'halothane, le sévoflurane et le desflurane ont été administrés à des groupes de rats selon des concentrations respectives de $0,1 \%, 0,3 \%$ et $0,6 \%$ à un débit $3 \mathrm{~L} \cdot \mathrm{min}^{-1} \mathrm{~d}^{\prime} \mathrm{O}_{2}$. Les animaux témoins ont aussi reçu $3 \mathrm{~L} \cdot \mathrm{min}^{-1} \mathrm{~d}^{\prime} \mathrm{O}_{2}$ dans un local d'expérimentation qui avait les même propriétés que le local du groupe à l'étude. Les rats ont respiré les anesthésiques d'inhalation ou de l'oxygène entre $9 \mathrm{~h}$ et $13 \mathrm{~h}$ tous les jours, pendant 30 jours. Après quoi, des tests de comportement ont été appliqués.

Résultats : Les tests d'activité exploratrice et de curiosité (planche trouée), d'anxiété (test de labyrinthe "elevated plus maze test») et des fonctions cognitive et mnésique («multiple $T$ maze test») ont démontré qu'une exposition chronique à des concentrations sous-anesthésiques des trois agents altèrent les comportements des rats. L'atteinte cognitive $(P<0,05)$ et mnésique $(P<0,05)$ $a$ été plus importante avec le desflurane, comparé à l'halothane et au sévoflurane.

Conclusion : L'exposition chronique à des concentrations sousanesthésiques d'halothane, de sévoflurane et de desflurane est associée à un changement de comportement chez les rats. Le desflurane a produit les scores les plus bas aux épreuves cognitives et mnésiques.

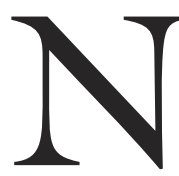
UMEROUS studies have suggested that chronic exposure to trace levels of anesthetic gases may be genotoxic, teratogenic, and may cause immunologic and systemic toxic problems. ${ }^{1-7}$ In pediatric anesthesia, mask induction with volatile agents and the use of pediatric semiclosed anesthesia circuits may result in even higher levels of anesthetic gases in the operating

From the Department of Anesthesiology and Reanimation, Ondokuz Mayis University, Faculty of Medicine, Samsun, Turkey. Address correspondence to: Dr. Sibel Baris, Ondokuz Mavıs Üniversitesi, Tıp Fakültesi, Anesteziyoloji ve Reanimasyon Anabilim Dalı, 55139, Kurupelit, Samsun, Turkey. E-mail: sbaris@omu.edu.tn

Financial support: institutional support.

Accepted for publication December 5, 2005.

Revision accepted February 9, 2006.

Competing interests: None declared. 
room. Furthermore, uncuffed endotracheal tubes are used widely in routine pediatric anesthesia practice and can cause considerable volatile anesthetic contamination in the operating room. This problem is especially important for operating room personnel who work in places with inadequate waste gas scavenging and airconditioning systems.

Long-term exposure to inhalation agents may cause headache, depression, anxiety, loss of appetite, loss of memory, and also changes in the intellectual function. ${ }^{8-11}$ Although the harmful effects of anesthetic gases on human health has been documented in several studies, behavioural effects of these agents have not been thoroughly examined. The aim of this study was to compare, using a rat model, the effects of chronic exposure to subanesthetic concentrations of halothane, sevoflurane and desflurane.

\section{Methods}

The experimental protocol was approved by the Institutional Animal Investigation Committee of Ondokuz Mayis University School of Medicine. Forty Wistar albino rats, eight months old (Ondokuz Mayis University Laboratory Animals, Samsun, Turkey), weighing 250-280 g were used. The animals were housed in groups of two or three in aluminium cages, and were maintained on a standard pellet food, tap water and normal day/night cycles, at an ambient temperature of $22 \pm 2^{\circ} \mathrm{C}$. Rats were divided into four groups of ten animals and allocated to halothane, sevoflurane, desflurane or control groups. All anesthetic exposures were conducted in a chamber of $50 \mathrm{~cm}$ width, $50 \mathrm{~cm}$ height and $100 \mathrm{~cm}$ length. The inspiratory gas inlet was on the upper border of the one side of anesthesia chamber. The expiratory gas outlet was located at the bottom of the anesthesia chamber on the controlateral side of the inspiratory gas inlet. A second exposure chamber with identical properties was used for the control animals.

Rats breathed inhaled agents or oxygen between 09:00-13:00 hr every day for 30 days. The equivalent of one minimal alveolar concentration of halothane, sevoflurane and desflurane in rats were considered to be $1.02,2.9$ and $6 \%$, respectively, based upon previous studies. ${ }^{12-14}$ The target exposed minimal alveolar concentrations of inhaled anesthetics were 1/10. Halothane, sevoflurane and desflurane groups received $0.1 \%, 0.3 \%$, and $0.6 \%$ concentrations, respectively, at a flow rate of $3 \mathrm{~L} \cdot \mathrm{min}^{-1} \mathrm{O}_{2}$ delivered through an anesthesia machine (Dameca, Denmark). Control subjects inhaled $3 \mathrm{~L} \cdot \mathrm{min}^{-1} \mathrm{O}_{2}$ only. The day after the 30-day inhaled anesthetic exposure behavioural tests were conducted in all groups at the same time of the day, as described below.

\section{Hole-board test}

The Hole-board test, which was described by File and Wardill in $1977,{ }^{15}$ is used for exploration, curiosity and locomotor activity in rodents, and provides an overview of an animal's behaviour in a single short test. The test arena consisted of a box (width $60 \mathrm{~cm}$, length $60 \mathrm{~cm}$ and height $40 \mathrm{~cm}$ ) with a board containing 16 round holes (diameter $4 \mathrm{~cm}$ ). Each rat was observed in the hole-board test arena for five minutes. The number of times the rat demonstrated the activity of head-dipping into the holes, and the duration of immobility, was assessed by a video camera and expressed in minutes.

\section{Elevated plus maze test}

Elevated plus maze test is a standard tool of research for anxiety in rats. The apparatus was identical to that described by Pellow et al. ${ }^{16}$ The test area is made of wood and consisted of two open arms (length $50 \mathrm{~cm}$, width $10 \mathrm{~cm}$ ) and two enclosed arms (length $50 \mathrm{~cm}$, width $10 \mathrm{~cm}$, height $40 \mathrm{~cm}$ ), which extended from a central $10 \mathrm{~cm} \times 10 \mathrm{~cm}$ square platform, configuring the maze into a 'plus' shape. The plus maze was elevated $50 \mathrm{~cm}$ above the floor. Each rat was placed in the centre of the maze facing an open arm, and was observed for five minutes. The times spent on the open and closed arms were recorded; the total time spent on open arms is considered to be related to anxiety.

\section{Multiple T maze test}

The multiple $\mathrm{T}$ maze test evaluates learning and memory functions. ${ }^{17}$ The test arena consisted of one starting box $(20 \mathrm{~cm} \times 20 \mathrm{~cm} \times 20 \mathrm{~cm})$, nine straight passages $(20 \mathrm{~cm} \times 10 \mathrm{~cm} \times 10 \mathrm{~cm})$, three blind boxes $(20 \mathrm{~cm} \times 10 \mathrm{~cm} \times 10 \mathrm{~cm})$ and two goal boxes $(20 \mathrm{~cm}$ $\times 20 \mathrm{~cm} \times 20 \mathrm{~cm})$. All rats received water once a day at 14:00 hr for three consecutive days before this test. In order to acclimatize the rats to the test area, each rat was allowed to explore the maze for five minutes with no reward, on the day prior to the experiment. During the test, a cup of water was placed in one goal box in the same position for both trials. Rats were then placed on the starting box. Time to locate the water cup, and the number of incorrect turns (leading to blind boxes) in five minutes were calculated from the video camera record. This test was repeated twice on consecutive days.

Following each experiment the test arenas were cleaned carefully with a disinfectant (alcohol) to remove any source of smell. All tests were continuously recorded with a video camera and evaluated by an observer blinded to group identity. 

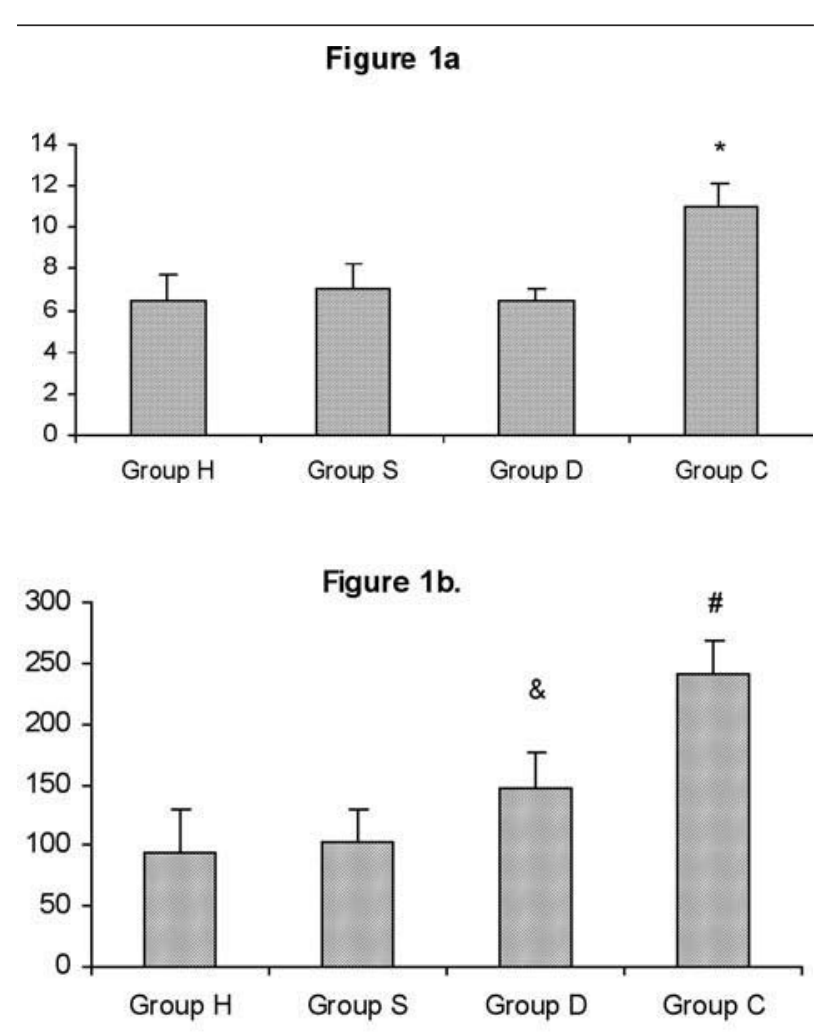

FIGURE $1 \mathrm{~A}$ and $1 \mathrm{~B}$ Head-dipping scores (1a) and exploratory time ( $1 \mathrm{~b})$ of groups in the hole board test. Group C: control group, Groups H, S and D: halothane, sevoflurane and desflurane groups, respectively. ${ }^{*} P<0.05$ vs halothane and desflurane groups in Figure la. $\# P<0.0001$ vs other groups, $\& P<0.005$ vs halothane and sevoflurane groups in Figure $1 \mathrm{~b}$.

\section{Statistical considerations}

Data were evaluated by Kruskal Wallis analysis of variance (ANOVA). When a factor was found significant $(P<0.05)$, subgroups were compared with the Mann-Whitney U test. Data are presented as mean \pm standard deviation. A $P<0.05$ was considered statistically significant. The SPSS for Windows, version 10.0, software package was used (SPSS Inc, Chicago, IL, USA).

\section{Results}

On the hole-board test, control animals demonstrated a greater number of head-dippings than all three anesthetic groups; the differences were significant in the halothane and desflurane groups $(P<0.05)$, but not in the sevoflurane group (Figure la). Control rats had longer exploratory times than the study groups $(P<$

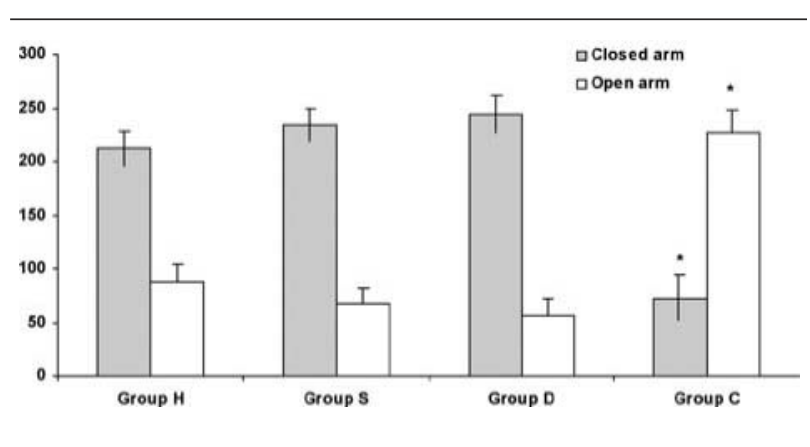

FIGURE 2 Time spent on the open and closed arms of the elevated plus maze test. Group C: control group, Groups $\mathrm{H}, \mathrm{S}$ and D: halothane, sevoflurane and desflurane groups, respectively. ${ }^{*} P<0.001$ vs other groups.

0.0001 , Figure lb). Amongst the anesthetic groups, exploratory time was longest in the desflurane group $(P<0.05 v s$ sevoflurane and halothane $)$.

In the elevated plus maze test, the percentage of time spent within the open arms in study groups was shorter than the control group $(23.7 \%, 20.9 \%, 16.6 \%$ and $72.2 \%$ in halothane, sevoflurane, desflurane and control groups, respectively, $P<0.0001$, Figure 2 ). In the multiple $\mathrm{T}$ maze test, control group rats found the water cup more quickly than did sevoflurane and desflurane-treated rats $(P<0.001)$ in the first trial (Figure 3a). In the second trial, time to finding the water cup was shorter in the control group in comparison to the other three groups in the multiple $\mathrm{T}$ maze test $(P<0.005)$. In the multiple $\mathrm{T}$ maze test, the number of wrong turns were significantly fewer in the control subjects than with the animals from other groups in the first trial (Figure $3 \mathrm{~b}$ ). The numbers of wrong turns was greatest in the desflurane group $(P<$ 0.005 compared to groups sevoflurane and halothane) in the second trial.

\section{Discussion}

The results of this study indicate that chronic exposure to subanesthetic concentrations of halothane, sevoflurane and desflurane results in modified exploratory behaviour and increased anxiety in rats. In addition, subanesthetic levels of halothane, sevoflurane and desflurane are associated with poorer scores in learning and memory tests.

The systemic effects of chronic exposure to inhalation anesthetics have been well documented, especially with respect to hepatic and renal function. ${ }^{7,18-20}$ However, behavioural changes associated with longterm exposure to these agents have not been investi- 


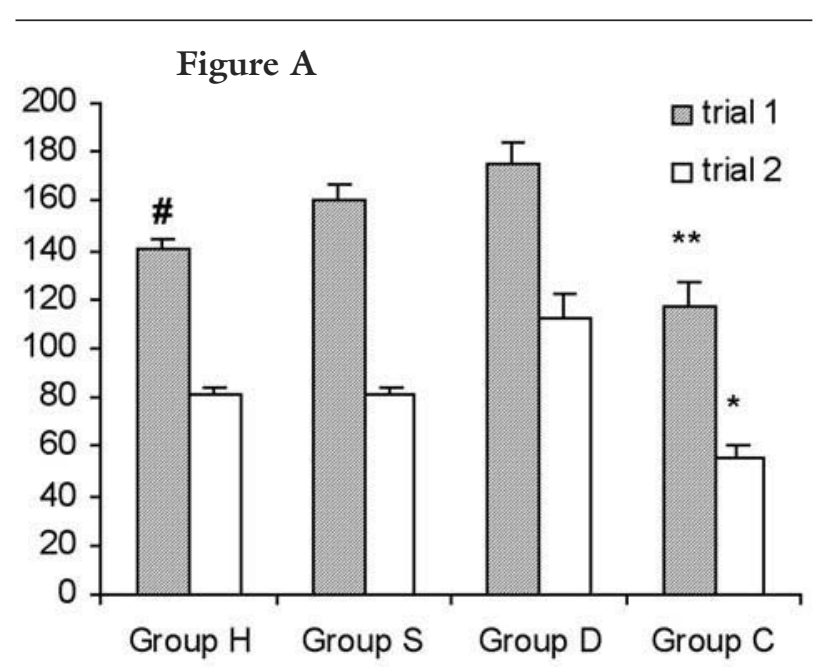

Figure B

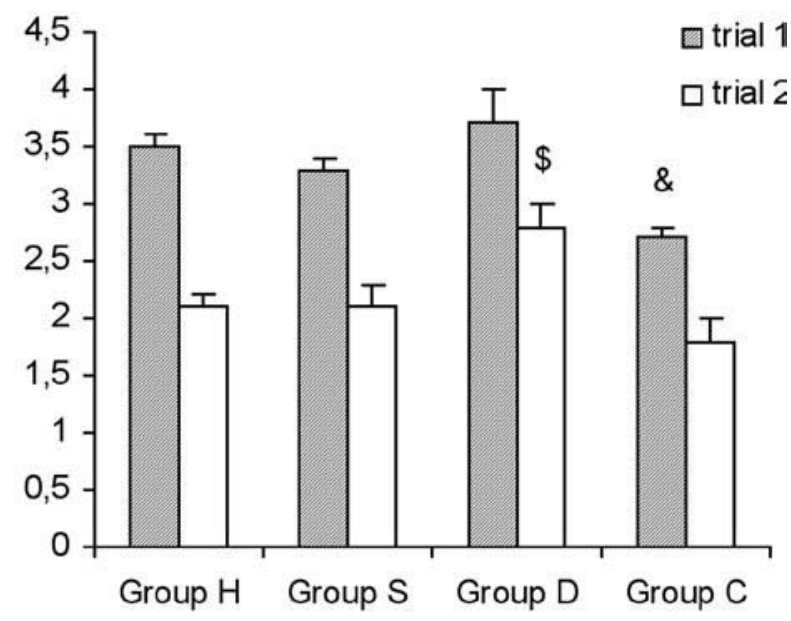

FIGURE 3A and 3B Time spent to find the water cup (3a) and the number of wrong turns $(3 \mathrm{~b})$ of the groups in the multiple T-maze test. Group C: control group, Groups H, S and $\mathrm{D}$ : halothane, sevoflurane and desflurane groups respectively. ${ }^{*} P<0.001$ vs sevoflurane and desflurane groups in trial $1, \# P<0.05$ vs desflurane group in trial $1,{ }^{*} P<0.005$ $v s$ all other groups in trial $2, \& p<0.05 v s$ all other groups in trial $1, \$ P<0.005$ vs all other groups in trial 2 .

gated in detail. The known adverse behavioural effects of inhalation anesthetics include impaired mental function, increased anxiety, impairment in psychomotor performance and learning. ${ }^{8-22}$ In some European countries, concentrations of inhalation anesthetics in operating rooms with active scavenging and airconditioning systems have been reported to vary between 53-2140 ppm for $\mathrm{N}_{2} \mathrm{O}, 0.7-11.3 \mathrm{ppm}$ for halothane, $0.3-1.4 \mathrm{ppm}$ for isoflurane, $0.02-0.2 \mathrm{ppm}$ for desflurane, and 0.03-0.16 ppm for sevoflurane. ${ }^{3,23}$ Concentrations of anesthetics to which rats were exposed in this study were substantially higher than trace concentrations encountered in most operating rooms with scavenging systems. On the other hand, if an operating room is not equipped with active scavenging devices or air conditioning systems, concentrations of inhalation anesthetics in the operating room air could approach subanesthetic concentrations in the immediate work area of the anesthesiologist. This is especially true for pediatric anesthesia, where inhalation induction via mask or uncuffed endotracheal tubes, or unsealed airway devices are used frequently. Thus, operating room personnel (anesthesiologists, surgical technicians and nurses) could potentially be at some risk of behavioural impairment and systemic toxicity due to chronic exposure to inhalation anesthetic agents.

Levin et al. ${ }^{9}$ showed that chronic exposure (30 or 60 days) to low levels of halothane (12.5 ppm) during intra-uterine development is associated with both neural and behavioural alterations in rats. In another clinical study, it was suggested that even low levels of exposure to anesthetic gases cause impairment of neurobehavioural performance in operating room personnel. ${ }^{24}$ In accordance with these findings, our results demonstrate that chronic exposure to subanesthetic levels of halothane, sevoflurane and desflurane may induce behavioural impairment in rats. Gentili et $a l^{25}$ have suggested that anesthesia with sevoflurane can pose a hazard of chronic exposure especially for anesthesiologists. Occupational exposure limits for sevoflurane and desflurane are not established, and behavioural changes related to chronic exposure and risks posed by their systemic toxicity on the health and professional performance of health-care personnel have not been thoroughly investigated.

Limitations in translating knowledge from animal experiments to humans must be considered in context of the benefits of these types of studies. Animals experiments can be performed in a more standardized fashion, verified easily, facilitate accurate data recording, and, finally allow use of objective parameters of behavioural function. There are numerous tests for studying curiosity, exploration, anxiety, learning and memory functions in rats. The classical hole-board test is used to investigate exploration, curiosity and locomotor activity in rodents. ${ }^{15}$ This test is based on the assumption that head-dipping of the animals is directly proportional to their curiosity and exploratory activity. ${ }^{26}$ In our study, 30-day exposure to subanes- 
thetic levels of inhaled agents decreased head-dipping in the hole-board test suggesting impairment in their curiosity. Exploratory time was also reduced in all study groups with respect to control groups, especially in halothane and sevoflurane exposed animals. These results suggest that halothane, sevoflurane and desflurane all suppress exploratory activity.

Elevated plus maze test is a widely used and wellvalidated test of anxiety. ${ }^{16}$ Exposure to the elevated plus maze test induces behavioural and physiological effects in rodents consistent with fear and anxiety. The animal is placed in the centre of an elevated four-arms maze where only two of the arms are enclosed and the reduction of time spent in the open arms reflects increased anxiety. Our results indicate that halothane, sevoflurane and desflurane caused anxiety. There is no previous publication evaluating the effects of inhalation agents on anxiety.

The multiple $\mathrm{T}$ maze test is used to assess the learning and memory functions in rodents ${ }^{17}$ but it has not been previously used to evaluate the effects of chronic exposure to inhalation agents on memory. Nevertheless, there are several studies performed for benzodiazepines and $5-\mathrm{HT}_{3}$ receptor antagonists, and it is a valid and reliable tool. ${ }^{27-29}$ Our multiple $\mathrm{T}$ maze test results indicate that learning and memory functions were depressed by inhalation agents, more obviously by desflurane.

New anesthetic chamber methods developed for anesthetizing non-intubated animals include monitoring $\mathrm{CO}_{2}$ levels. ${ }^{30,31}$ The lack of $\mathrm{CO}_{2}$ monitoring in the anesthetic chamber is a limitation in our study. On the other hand, although high $\mathrm{CO}_{2}$ levels cause adverse effects on the psychomotor responses of rats, our control group rats were also exposed to the same conditions. We therefore believe that results from the anesthetic groups and the control group can be attributed to anesthetic exposure. Furthermore, a fresh gas flow rate of $3 \mathrm{~L} \cdot \mathrm{min}^{-1}$ to the chamber provides twice the minute ventilation of rats (minute ventilation is $160 \mathrm{~mL}$ for one rat and $1600 \mathrm{~mL}$ for a group of ten rats) and it is therefore unlikely that $\mathrm{CO}_{2}$ retention was a confounding variable in our study. Finally, we performed the behavioural tests only after 30 days of exposure to subanesthetic levels of inhalation anesthetics. Therefore, we cannot speculate as to whether these changes are transient or persistent in nature. However, operating room personnel may be exposed to trace levels of these agents throughout their occupational life, and subanesthetic concentrations could occur.

In conclusion, our study shows that 30-day exposure to subanesthetic concentrations of halothane, sevoflurane and desflurane is associated with impaired curiosity, exploratory behaviour, increased anxiety, and impaired learning and memory functions in rats. These findings emphasize the importance of procedures and periodic monitoring to ensure that exposure to these agents in the operating room is minimized. Effects of more prolonged exposure of both trace and subanesthetic levels of inhalation agents warrant further investigation.

\section{Acknowledgement}

We thank Prof. Dr. Y. Sancar Baris for his critical review of this manuscript.

\section{References}

1 Chang WP, Lee S, Tu J, Hseu S. Increased micronucleus formation in nurses with occupational nitrous oxide fexposure in operating theaters. Environ Mol Mutagen 1996; 27: 93-7.

2 Karelova J, Jablonicka A, Gavora J, Hano L. Chromosome and sister-chromatid exchange analysis in peripheral lymphocytes, and mutagenicity of urine in anesthesiology personnel. Int Arch Occup Environ Health 1992; 64: 303-6.

3 Wiesner G, Hoerauf K, Schroegendorfer K, Sobczynski P, Harth M, Ruediger HW. High-level, but not low-level, occupational exposure to inhaled anesthetics is associated with genotoxicity in the micronucleus assay. Anesth Analg 2001; 92: 118-22.

4 Atallah MM, Motawea AA, El-Chennawy FA, Attallah $A F$. Immunological assays following exposure to halothane in clinical usage. Eur J Anaesthesiol 1991; 8: 459-64.

5 Guirguis SS, Pelmear PL, Roy ML, Wong L. Health effects associated with exposure to anaesthetic gases in Ontario hospital personnel. Br J Ind Med 1990; 47 : 490-7.

6 Lind RC, Gandolfi AJ, Hall PD. Subanesthetic halothane is hepatotoxic in the Guinea pig. Anesth Analg 1992; 74: 559-63.

7 Stevens WC, Eger EI II, White A, et al. Comparative toxicities of halothane, isoflurane, and diethyl ether at subanesthetic concentrations in laboratory animals. Anesthesiology 1975; 42: 408-19.

8 Cook TL, Smith M, Starkweather JA, Winter PM, Eger EI II. Behavioral effects of trace and subanesthetic halothane and nitrous oxide in man. Anesthesiology 1978; 49: 419-24.

9 Levin ED, Bowman RE. Behavioral effects of chronic exposure to low concentrations of halothane during development in rats. Anesth Analg 1986; 65: 653-9.

10 Zacny JP, Sparacino G, Hoffmann PM, Martin R, Lichtor JL. The subjective, behavioral and cognitive effects of subanesthetic concentrations of iso- 
flurane and nitrouse oxide in healthy volunteers. Psychopharmacology (Berl) 1994; 114: 409-16.

11 Zacny JP, Yajnik S, Lichtor JL, et al. The acute and residual effects of subanesthetic concentrations of isoflurane/nitrous oxide combinations on cognitive and psychomotor performance in healthy volunteers. Anesth Analg 1996; 82: 153-7.

12 Dimaculangan D, Bendo AA, Sims R, Cottrell JE, Kass $I S$. Desflurane improves the recovery of the evoked postsynaptic population spike from CAl pyramidal cells after hypoxia in rat hippocampal slices. J Neurosurg Anesthesiol 2006; 18: 78-82.

13 Steffey MA, Brosnan RJ, Steffey EP. Assessment of halothane and sevoflurane anesthesia in spontaneously breathing rats. Am J Vet Res 2003; 64: 470-4.

14 Haelewyn B, Yvon A, Hanouz JL, et al. Desflurane affords greater protection than halothane against focal cerebral ischaemia in the rat. Br J Anaesth 2003; 91: 390-6.

15 File SE, Wardill AG. The reliability of the hole-board apparatus. Psychopharmacologia 1975; 14: 47-51.

16 Pellow S, File SE. Anxiolytic and anxiogenic drug effects on exploratory activity in an elevated plus-maze: a novel test of anxiety in the rat. Pharmacol Biochem Behav 1986; 24: 525-9.

17 Timberlake $W$. Niche-related learning in laboratory paradigms: the case of maze behavior in Norway rats. Behav Brain Res 2002; 134: 355-74.

18 Plummer JL, Hall PD, Cousins MJ, Bastin FM, Ilsley $A H$. Hepatic injury in rats due to prolonged subanaesthetic halothane exposure. Acta Pharmacol Toxicol 1983; 53:16-22.

19 Plummer JL, Hall PD, Jenner MA, Ilsley AH, Cousins $M J$. Effects of chronic inhalation of halothane, enflurane or isoflurane in rats. Br J Anaesth 1986; 58: 517-23.

20 Nilsson R, Björdal C, Andersson M, et al. Health risks and occupational exposure to volatile anaesthetics - a review with a systematic approach. J Clin Nurs 2005; 14: 173-86.

21 Bruce DL, Bach MJ, Arbit J. Trace anesthetic effects on perceptual, cognitive and motor skills. Anesthesiology 1974; 40: 453-8.

22 Bruce DL, Bach MJ. Effects of trace anaesthetic gases on behavioural performance of volunteers. $\mathrm{Br} \mathrm{J}$ Anaesth 1976; 48: 871-5.

23 Mierdl S, Byhahn C, Abdel-Rahman U, Matheis G, Westphal K. Occupational exposure to inhalational anesthetics during cardiac surgery on cardiopulmonary bypass. Ann Thorac Surg 2003; 75: 1924-7.

24 Lucchini R, Placidi D, Toffoletto F, Alessio L. Neurotoxicity in operating room personnel working with gaseous and nongaseous anesthesia. Int Arch
Occup Environ Health 1996; 68: 188-92.

25 Gentili A, Accorsi A, Pigna A, et al. Exposure of personnel to sevoflurane during paediatric anaesthesia: influence of professional role and anaesthetic procedure. Eur J Anaesthesiol 2004; 21: 638-45.

26 Takeda H, Tsuji M, Matsumiya T. Changes in headdipping behavior in the hole-board test reflect the anxiogenic and/or anxiolytic state in mice. Eur J Pharmacol 1998; 350: 21-9.

27 Graeff FG, Viana M, Tornaz C. The elevated T maze, a new experimental model of anxiety and memory: effect of diazepam. Brazil J Med Biol Res 1993; 26: 67-70.

28 Gargiulo PA, Viana MB, Graeff FG, de Souza Silva $M A$, Tomaz C. Effects on anxiety and memory of systemic and intra-amygdala injection of $5-\mathrm{HT}_{3}$ receptor antagonist BRL 46470A. Neuropsychobiology 1996; 33: 189-95.

29 Tomaz C, Dickinson-Anson H, McGaugh JL, de Souza Silva $M A$, Viana $M B$, Graeff FG. Localization in the amygdala of the amnestic action of diazepam on emotional memory. Behav Brain Res 1993; 58: 99-105.

30 Sonner JM, Li J, Eger EI II. Desflurane and the nonimmobilizer 1,2-dichlorohexafluorocyclobutane suppress learning by a mechanism independent of the level of unconditioned stimulation. Anesth Analg 1998; 87: 200-5.

31 Butterfield NN, Ries CR, Macleod BA. An inexpensive, calibrated closed system to induce and maintain anesthesia in mice. Proc West Pharmacol Soc 2001; 44: 7-8. 